\title{
Epidemiological features and risks of hemangiomas
}

\author{
Gürses Şahin ${ }^{1}$, Duygu Düzcan-Kilimci², Hikmet Gülşah Tanyıldız \\ Departments of ${ }^{1}$ Pediatric Oncology and Hematology, and ${ }^{2}$ Pediatrics, Dr. Sami Ulus Maternity and Children's Health \\ and Diseases Training and Research Hospital, Ankara, Turkey.Email: g_oktay4910@yahoo.com \\ Received: 28th April 2017, Revised: 29th May 2017, Accepted: 1st June 2017
}

SUMMARY: Şahin G, Düzcan-Kilimci D, Tanyıldız HG. Epidemiological features and risks of hemangiomas. Turk J Pediatr 2017; 59: 664-669.

Hemangiomas are the most common benign tumors of childhood. The known risk factors in developing hemangiomas are female gender, prematurity and low birth weight. Our study was designed to investigate prenatal and natal risk factors in addition to the above factors that would potentially affect development of hemangiomas. Two hundred forty hemangioma patients and 100 healthy controls were included in the study. Both groups were interviewed for age, gender, prenatal characteristics (presence of maternal pregnancy hypotension, hypertension and hyperemesis, parental smoking habits) as well as natal characteristics (delivery, birth weight, gestational age) and maternal-paternal age. Hemangiomas were mostly localized in the head and neck. Risk of developing hemangioma was higher in girls and in firstlings. History of hyperemesis during pregnancy increased incidence of hemangioma. Post-term delivery was found to be protective against developing hemangioma. We are in the opinion that there is a need for wider studies with a bigger sample size so as to detect other risk factors.

Key words: hemangioma, pregnancy, hyperemesis, risk factors.

Hemangiomas are the most common benign vascular tumors of childhood. Although their pathogenesis remains highly unclear, they are thought to be triggered by fetal hypoxic stress. ${ }^{1-3}$ Genetic causes and environmental factors probably coexist. This study aims at investigating epidemiological characteristics of hemangiomas by a special focus on sociodemographics, prenatal and natal risk factors, as well as parental age of cases admitted to our clinic and diagnosed with hemangioma during delivery.

\section{Material and Methods}

Two hundred forty hemangioma patients having been admitted to the Pediatric Hematology and Oncology Division between 2008-2016 and 100 healthy children at routine controls were retrospectively screened from hospital record in terms of etiological and epidemiological factors (socio-demographic, prenatal, natal). We aimed at specifying age, gender, prenatal characteristics (presence of maternal gestational hypotension, hypertension and hyperemesis, parental smoking habits) as well as natal characteristics (delivery, birth weight, gestational age) and maternal - paternal age characteristics of hemangioma patients, retrospectively.

The research was reviewed and approved by an Institutional Review Board (26 July 2016; 73799008).

\section{Statistical Analysis}

When assessing findings of the study, SPSS (Statistical Package for Social Sciences) for Windows 21.0 software was used for statistical analyses. In addition to complementary statistical methods (mean, standard deviation, frequency), Chi-square test and Fisher's exact test were used for qualitative comparisons. Results were evaluated at a confidence interval of $95 \%$ and at significance level of $\mathrm{p}<0.05$.

\section{Results}

A total of 340 subjects were included in the study: 240 hemangioma patients and 100 healthy controls. One hundred fifty-seven (65.4\%) of 240 hemangioma patients were female, $83(34.6 \%)$ were male; whereas 
$46(46 \%)$ of healthy controls were female and 54 (54\%) were male. Hemangioma risk increased by 2.22 folds in girls $(95 \% \mathrm{CI}$ 1.38-3.57; $\mathrm{p}=0.001)$. Eighty-one percent of hemangiomas and $61 \%$ of healthy controls were under the age of 1 ; whereas $89.2 \%$ of hemangioma patients and $80 \%$ of healthy controls were under 2. Hemangioma was present at birth in $114(47.5 \%)$ cases whereas in $126(52.5 \%)$ was diagnosed after birth. Five patients $(2.08 \%)$ in the case group and 2 cases $(2 \%)$ in the control group were twin pairs. Fifty-five percent of hemangiomas were localized at the head and neck, $22 \%$ on the trunk, $9 \%$ in lower extremities, $7 \%$ in upper extremities, $2 \%$ at genitals and $5 \%$ at multiple sites.

Mothers of $40(16.7 \%)$ children with hemangiomas and of 17 (17\%) healthy controls were smokers prior to pregnancy. Thirty $(12.5 \%)$ mothers of hemangioma patients and $17(17 \%)$ of healthy controls smoked during pregnancy. One hundred thirty-seven $(57.1 \%)$ fathers of hemangioma patients and 68 (68\%) of healthy children were smokers. There was no statistically significant association between parent's smoking habits and hemangioma incidence ( $p>0.05$; Table I). Forty-three (17.9\%) mothers of hemangioma patients and $26(74 \%)$ of healthy controls reported hypotension during pregnancy. Twenty-two $(8.3 \%)$ mothers of hemangioma patients and 9 (9\%) of healthy controls had hypertension history during pregnancy. Hypertension or hypotension during pregnancy did not increase the risk of hemangioma $(\mathrm{p}=0.091, \mathrm{p}=0.841)$. One hundred thirty-five (56.3\%) mothers of hemangioma patients and 44 (44\%) of healthy controls reported hyperemesis during pregnancy. There was a significant relationship between hyperemesis during pregnancy and development of hemangioma $(p=0.039)$. Presence of hyperemesis in pregnancy increased the risk of developing hemangioma by 1.64 folds (\%95 CI 1.02-2.62; $\mathrm{p}=0.039$; Table II).

Thirty-five (14.6\%) mothers and $53(22.1 \%)$ fathers of hemangioma patients, and 17 $(17 \%)$ mothers and 34 (34\%) fathers of healthy controls were above 35 years of age. Maternal age did not correlate with presence of hemangioma significantly $(p=0.573)$ whereas paternal age $<35$ years presented a significant correlation with presence of hemangioma $(p=0.022)$. Paternal age $<35$ years increased the hemangioma risk by 1.82 folds $(95 \% \mathrm{CI}$ 1.09-3.04).

One hundred twenty (50\%) of hemangioma patients are firstborn and $77(32.1 \%)$ are second born children; whereas 28 (28\%) of non-hemangioma patients are firstborn and $41(41 \%)$ are second born children. Being the firstborn child increased the risk of hemangioma by 3.09 folds (\%95 CI 1.66-5.73; $\mathrm{p}<0.001)$. Forty-five $(18.8 \%)$ of hemangioma patients were born before 37 weeks, 191 (79.6\%) between 37-40 weeks and 4 after 40 weeks. Sixteen (16\%) of non-hemangioma patients were born before 37 weeks, 78 (78\%) between weeks $37-40$ and $6(6 \%)$ after week 40 . Being born beyond the $40^{\text {th }}$ week reduced

Table I. Smoking Habits of Parents of Patients with Hemangioma and Healthy Subjects.

\begin{tabular}{|c|c|c|c|c|c|c|c|}
\hline \multirow[t]{2}{*}{ Smoking habits of parents } & \multicolumn{2}{|c|}{$\begin{array}{l}\text { Patients with } \\
\text { hemangioma }\end{array}$} & \multicolumn{2}{|c|}{ Healthy subjects } & \multicolumn{2}{|c|}{ Odds ratio } & \multirow[t]{2}{*}{$\mathrm{p}$} \\
\hline & $\mathrm{N}$ & $\%$ & $\mathrm{~N}$ & $\%$ & OR & $95 \% \mathrm{CI}$ & \\
\hline \multicolumn{8}{|l|}{$\begin{array}{l}\text { Maternal smoking before } \\
\text { pregnancy }\end{array}$} \\
\hline Yes & 40 & 16.7 & 17 & 17.0 & 0.95 & $0.52-1.82$ & 0.940 \\
\hline No & 200 & 83.3 & 83 & 83.0 & & & \\
\hline \multicolumn{8}{|l|}{$\begin{array}{l}\text { Maternal smoking during } \\
\text { pregnancy }\end{array}$} \\
\hline Yes & 30 & 12.5 & 17 & 17.0 & 0.69 & $0.36-1.33$ & 0.273 \\
\hline No & 210 & 87.5 & 83 & 83.0 & & & \\
\hline \multicolumn{8}{|l|}{ Paternal smoking } \\
\hline Yes & 137 & 57.1 & 68 & 68.0 & 0.62 & $0.38-1.02$ & 0.061 \\
\hline No & 103 & 42.9 & 32 & 32.0 & & & \\
\hline
\end{tabular}

CI: confidence interval 
hemangioma risk by 2.7 folds $(\mathrm{p}=0.036$; Table III). Forty-four (18.3\%) of hemangioma patients had birth weight under 2,500 g, 182 (75.8\%) between $2500-4000 \mathrm{~g}$ and 14 (1.7\%) above 4000 g. Eight (8\%) of non-hemangioma patients had low birth weight; low birth weight had a 2.48 folds raised hemangioma risk versus children with normal birth weight, which was statistically significant $(95 \%$ CI 1.12-5.50; $\mathrm{p}=0.022$; Table III).

\section{Discussion}

Hemangiomas are the most common benign vascular tumors of childhood and have a 2-3 fold higher incidence in girls than in boys. ${ }^{1-3}$ Concomitant with the literature, our study presented with a 2.2 fold higher incidence in girls. Yet, it remains unclear why girls have a higher hemangioma incidence. Nevertheless, estrogen is thought to be responsible for enhancing endothelial cell proliferation. ${ }^{4}$ In a study done on related hemangioma patients, it was stated that a group of hemangiomas may be hereditary and may be associated with genes on the $5^{\text {th }}$ chromosome but the same study failed to detect any mutation on the $\mathrm{X}$ chromosome. ${ }^{5}$ Some researchers defend the view that families tend to take their girls to doctor more often for cosmetic concerns and this should be considered as a reason why the disease is relatively more diagnosed in girls. ${ }^{1}$

Our study did not find any association between smoking habits of mothers before or during pregnancy and the risk of developing hemangioma. Yet it was observed that incidence of hemangioma tended to decrease when their mothers quit smoking during pregnancy. Interestingly, fathers' smoking habit was found to be protective against developing hemangioma. There is no study in the literature on this topic. Father's smoking may be leading to positive selection of hypoxiaresistant sperms laying the background for epigenetic changes with adaptation to hypoxia. Furthermore, high smoking ratio may have led to this result as a confounding factor. There is a need for larger scaled studies on this topic.

Hypoxia is one of the major factors blamed in the pathogenesis of hemangioma. GLUT1 , a marker in hemangioma is a significant perceiver of hypoxia. GLUT-1 was found to have increased in hypoxic sites of mesenchymal tumors as well as in mesenchymal stem cells of the umbilical cord under hypoxic conditions. ${ }^{6,7}$ Some hypoxia-associated factors including VEGF-A and MMP-9 were found in elevated levels in blood and hypoxiainduced factor 1 alpha, MMP-9 and VEGF-A in hemangioma tissue in proliferation. ${ }^{8}$ Placental and perinatal hypoxia may cause an increase in hemangioma incidence due to these reasons. In a study by Li et al. ${ }^{9}$ no association was found between parental smoking and development of hemangioma. Kim et al. ${ }^{10}$ on the other hand, reported higher incidence of hemangioma in children born from unplanned pregnancies of smoking mothers. This was explained by the fact that mothers tend to quit smoking when they plan pregnancy due to scared side effects. ${ }^{11}$ On the other hand, smoking has a protective effect against preeclampsia due to its proangiogenic effects (increased

Table II. History of Hypotension, Hypertension and Hyperemesis During Pregnancy of Mothers of Patients with Hemangioma and Healthy Subjects.

\begin{tabular}{|c|c|c|c|c|c|c|c|}
\hline \multirow{2}{*}{$\begin{array}{l}\text { Maternal history during } \\
\text { pregnancy }\end{array}$} & \multicolumn{2}{|c|}{$\begin{array}{l}\text { Patients with } \\
\text { hemangioma }\end{array}$} & \multicolumn{2}{|c|}{ Healthy subjects } & \multicolumn{2}{|c|}{ Odds ratio } & \multirow[t]{2}{*}{$\mathrm{p}$} \\
\hline & $\mathrm{N}$ & $\%$ & $\mathrm{~N}$ & $\%$ & OR & $95 \% \mathrm{CI}$ & \\
\hline \multicolumn{8}{|l|}{ Hypotension } \\
\hline Yes & 43 & 17.9 & 26 & 26.0 & 0.62 & $0.36-1.08$ & 0.091 \\
\hline No & 197 & 82.1 & 74 & 74.0 & & & \\
\hline \multicolumn{8}{|l|}{ Hypertension } \\
\hline Yes & 22 & 8.3 & 9 & 9.0 & 0.92 & $0.40-2.09$ & 0.841 \\
\hline No & 220 & 91.7 & 91 & 91.0 & & & \\
\hline \multicolumn{8}{|l|}{ Hyperemesis } \\
\hline Yes & 135 & 56.3 & 44 & 44.0 & 1.64 & $1.02-2.62$ & 0.039 \\
\hline No & 105 & 43.8 & 56 & 56.0 & & & \\
\hline
\end{tabular}

CI: confidence interval 
placental growth factor and diminished soluble endoglin and anti-antigiogenic VEGF receptor $1)$. This proangiogenic effect of smoking may be considered as a secondary reaction against anemia and hypoxia. ${ }^{12}$ Maternal smoking has been shown to decrease placental blood flow. It has been speculated that placental hypoperfusion is resulting from vasoconstrictive effects of nicotine. Vasoconstrictive effects of nicotine on uterine and umbilical arteries increases carboxyhemoglobin concentrations that interfere with oxygenation. As a result, smoking leads to hyperplasia in cytotrophoblasts in order to increase surface area by angiogenesis and neovascularization. ${ }^{13}$ A similar mechanism may also be explained by the rise in hemangioma incidence in preterm infants using erythropoietin. Anemia, as a stimulant for erythropoiesis and angiogenesis probably also stimulates the development of hemangioma. ${ }^{14}$

Our study failed to detect a significant relationship between hypotension history during mother's pregnancy and development of hemangioma. There is no study reported in the literature on this aspect. Hypotension is known to impair tissue perfusion. It may also contribute to development of hemangioma by causing hypoxia. Yet, since only symptomatic hypotensive cases were included in our case group the result may be statistically nonsignificant.

Our study did not find any significant difference between history of hypertension during pregnancy and development of hemangioma. The literature primarily investigates the relationship between preeclampsia (rather than history of hypertension) and the risk of developing hemangioma. The role of preeclampsia remains unclear in development of hemangioma but some placental growth factors may be playing part in its development. Placental growth factor (PIGF) is more prominent in preeclampsia patients. PIGF was shown to be expressed immunohistochemically in hemangiomas, which supports the hypothesis that the placenta and hemangiomas grow from similar vascular origins. ${ }^{15}$ In a study conducted by Munden et al. ${ }^{16}$ preeclampsia was found to increase the risk of developing hemangioma.

Those having history of hyperemesis during their pregnancy had a 1.64-fold higher risk of developing hemangioma. Hyperemesis gravidarum is defined as persistent attacks of nausea and vomiting to the extent of hospitalization. ${ }^{17}$ Studies indicate that hyperemesis may cause intrauterine growth restriction, low birth weight and diseases like type 2 diabetes in the fetus. ${ }^{18,19}$ Hyperemesis may cause development of hemangioma due to hypoxia secondary to perfusion impairment. Another study done on the same topic failed to present a significant relationship between the history of extreme vomiting during pregnancy and development of hemangioma. ${ }^{9}$ We are in the opinion that there is the need for further research work to be done on the association of developing hemangioma and hyperemesis.

We did not find any rise in the incidence of hemangioma in children of mothers having

Table III. Gestational Age and Birth Weight of Patients with Hemangioma and Healthy Subjects.

\begin{tabular}{|c|c|c|c|c|c|c|c|}
\hline & \multicolumn{2}{|c|}{$\begin{array}{l}\text { Patients with } \\
\text { hemangioma }\end{array}$} & \multicolumn{2}{|c|}{ Healthy subjects } & \multicolumn{2}{|c|}{ Odds Ratio } & \multirow[t]{2}{*}{$\mathrm{p}$} \\
\hline & $\mathrm{N}$ & $\%$ & $\mathrm{~N}$ & $\%$ & OR & $95 \% \mathrm{CI}$ & \\
\hline \multicolumn{8}{|l|}{ Gestational age } \\
\hline$<37$ weeks & 45 & 18.8 & 16 & 16.0 & 1.15 & $0.61-$ & 0.666 \\
\hline 37-40 weeks & 191 & 79.6 & 78 & 78.0 & 1.00 & 2.15 & \\
\hline \multirow{2}{*}{$>40$ weeks } & 4 & 1.7 & 6 & 6.0 & 0.27 & & 0.036 \\
\hline & & & & & $\begin{array}{l}0.08- \\
0.99\end{array}$ & \\
\hline $\begin{array}{l}\text { Birth weight } \\
<2500 \mathrm{~g}\end{array}$ & & 18.3 & 8 & 8.0 & 2.48 & $1.12-$ & 0.022 \\
\hline $2500-4000 \mathrm{~g}$ & 182 & 75.8 & 82 & 82.0 & 1.00 & 5.50 & \\
\hline \multirow{2}{*}{$>4000 \mathrm{~g}$} & 14 & 5.8 & 10 & 10.0 & 0.63 & & 0.286 \\
\hline & & & & & & $\begin{array}{l}0.27- \\
1.48\end{array}$ & \\
\hline
\end{tabular}


delivered at a more advanced age. In a study by Haggstrom et al. ${ }^{1} 55.1 \%$ of mothers of hemangioma patients were found at the age of 30 and beyond concluding that advanced maternal age is a statistically significant factor in developing hemangioma compared to the general population. Advanced maternal age may be causing this increase in incidence of hemangioma indirectly because it more associated with complications of pregnancy such as preterm delivery, low birth weight and preeclampsia. ${ }^{1}$ Paternal age under 35 increased the risk of developing hemangioma. This may be explained by presence of agerelated confounding factors in the control group or epigenetic suppression of some factors causing hemangioma with age during spermatogenesis.

Fifty percent of the hemangioma patients included in the study were firstlings, and being the firstborn child increased the risk of developing hemangioma by 3.09 folds. Other studies also reported higher incidence of hemangioma in firstlings. ${ }^{20}$ This increase was explained by higher incidence of preeclampsia in first pregnancies. ${ }^{1,21}$

Our study failed to observe a significant relationship between prematurity and development of hemangioma, whereas hemangioma was less frequently observed in infants born beyond 40 weeks. Hemangiomas are more common in premature or low birth weight infants. In a study by Amir et al. ${ }^{22}, 13 \%$ of 973 preterm infants developed hemangioma, which is (10\%) more frequent than the predicted level. Higher incidence of hemangioma among preterm infants may be explained by the imbalance in angiogenic shock mechanisms ${ }^{1}$. Previous studies did not investigate the association between being born beyond 40 weeks and development of hemangioma, which may be explained as follows: babies born beyond 40 weeks are generally the ones having completed their overall development and are less exposed to factors such as intrauterine hypoxia. This may be the reason why hemangiomas are less common in these babies.

The incidence of hemangioma was 2.48 folds higher in low birth weight infants. In Amir's study, the incidence was found as high as $22-30 \%$ in infants under 1000 g. ${ }^{22}$ A study by Drolet et al. ${ }^{23}$ suggested that every $500 \mathrm{~g}$ of loss in birth weight increased the risk of developing hemangioma by $25 \%$ and that low birth weight is a more important risk factor than age.

Multiple pregnancies are also among the known risk factors for development of hemangioma. Two percent of our subjects both in the hemangioma and control groups were twin pairs, and there was no statistically significant difference amongst the two groups. Higher incidence of hemangioma in multiple pregnancies can be explained by prematurity and the effect of progesterone. The risk of developing hemangioma apparently increases in in vitro fertilization pregnancies due to higher probability of multiple pregnancies. ${ }^{10}$ In a study done with more than 118 twins, there was no statistically significant difference in hemangioma incidence among monozygotic and dizygotic twins. Monozygotic twins also did not present an increased incidence of hemangioma within their own group, which shows that hereditary factors are not dominant factors in development of hemangioma and that hemangioma is more common among twin pairs with lower birth weight. ${ }^{24}$

The retrospective nature of our study is a major limitation to detect the real frequency of the probable factors causing hemangioma. Authors of the study are in the opinion that there is a need for more extensive prospective research work to be done in this field to conclude that these factors constitute an absolute risk for development of hemangioma.

In conclusion, beyond known risk factors, hyperemesis was found to present a risk factor for developing hemangioma whereas post-maturity was suggested as a protective factor against hemangioma.

\section{REFERENCES}

1. Haggstrom AN, Drolet BA, Baselga E, et al. Prospective study of infantile hemangiomas: Demographic, prenatal, and perinatal characteristics. J Pediatr 2007; 150: 291294.

2. Bree AF, Siegfried E, Sotelo-Avila C, Nahass G. Infantile hemangiomas: Speculation on placental trophoblastic origin. Arch Dermatol 2001; 137: 573 577.

3. Finn MC, Glowacki J, Mulliken JB. Congenital vascular lesions: Clinical application of a new classification. J Pediatr Surg 1983; 18: 894-900. 
4. Sasaki GH, Pang CY, Wittliff JL. Pathogenesis and treatment of infant skin strawberry hemangiomas: Clinical and in vitro studies of hormonal effects. Plast Reconstr Surg 1984; 73: 359-370.

5. Berg JN, Walter JW, Thisanagayam U, et al. Evidence for loss of heterozygosity of $5 q$ in sporadic haemangiomas: Are somatic mutations involved in haemangioma formation? J Clin Pathol 2001; 54: 249-252.

6. Dai Y, Hou F, Buckmiller L, Fan CY, Saad A, Suen J, et al. Decreased eNOS protein expression in involuting and propranolol-treated hemangiomas. Arch Otolaryngol Head Neck Surg 2012; 138: 177-182.

7. Ahrens WA, Ridenour RV III, Caron BL, Miller DV, Folpe AL. GLUT-1 expression in mesenchymal tumors: An immunohistochemical study of 247 soft tissue and bone neoplasms. Hum Pathol 2008; 39: 1519-1526.

8. Kleinman ME, Blei F, Gurtner GC. Circulating endothelial progenitor cells and vascular anomalies. Lymphat Res Biol 2005; 3: 234-239.

9. Li J, Chen X, Zhao S, et al. Demographic and clinical characteristics and risk factors for infantile hemangioma: A Chinese case-control study. Arch Dermatol 2011; 147: 1049-1056.

10. Kim EJ, Park HS, Yoon HS, Cho S. Maternal and perinatal factors of importance for occurrence and severity of infantile haemangioma. Acta Derm Venereol 2015; 95: 696-699.

11. Jeyabalan A, Powers RW, Durica AR, Harger GF, Roberts JM, Ness RB. Cigarette smoke exposure and angiogenic factors in pregnancy and preeclampsia. Am J Hypertens 2008; 21: 943-947.

12. Jeyabalan A, Powers RW, Clifton RG, et al. Eunice Kennedy Shriver National Institute of Child Health and Human Development Maternal-Fetal Medicine Units Network. Effect of smoking on circulating angiogenic factors in high risk pregnancies. PLoS One 2010; 5: 13270.

13. Kaminsky LM, Ananth CV, Prasad V, Nath CA, Vintzileos AM. The influence of maternal cigarette smoking on placental pathology in pregnancies complicated by abruption. Am J Obstet Gynecol 2007; 197: 275.
14. Doege C, Pritsch M, Frühwald MC, Bauer J. An association between infantile haemangiomas and erythropoietin treatment in preterm infants. Arch Dis Child Fetal Neonatal Ed 2012; 97: 45-49.

15. Levine RJ, Karumanchi SA. Circulating angiogenic factors in preeclampsia. Clin Obstet Gynecol 2005; 48: $372-386$

16. Munden A, Butschek R, Tom WL, et al. Prospective study of infantile hemangiomas: Incidence, clinical characteristics, and association with placental anomalies. Br J Dermatol 2014; 170: 907-913.

17. Abell TL, Riely CA. Hyperemesis gravidarum. Gastroenterol Clin North Am 1992; 21: 835-849.

18. Veenendaal MV, van Abeelen AF, Painter RC, van der Post JA, Roseboom TJ. Consequences of hyperemesis gravidarum for offspring: a systematic review and meta-analysis. BJOG 2011; 118: 1302-1313.

19. Kontic-Vucinic O, Sulovic N, Radunovic N Micronutrients in women's reproductive health: I. Vitamins. Int J Fertil Womens Med 2006; 51: 106-115.

20. Hoornweg MJ, Smeulders MJ, Ubbink DT, van der Horst CM. The prevalence and risk factors of infantile haemangiomas: A case-control study in the Dutch population. Paediatr Perinat Epidemiol 2012; 26: 156162.

21. Funai EF, Paltiel OB, Malaspina D, Friedlander Y, Deutsch L, Harlap S. Risk factors for pre-eclampsia in nulliparous and parous women: The Jerusalem perinatal study. Paediatric and Perinatal Epidemiology 2005; 19: 59-68.

22. Amir J, Metzker A, Krikler R, Reisner SH. Strawberry hemangioma in preterm infants. Pediatr Dermatol 1986; 3: 331-332.

23. Drolet BA, Swanson EA, Frieden IJ, Hemangioma Investigator Group. Infantile hemangiomas: A n emerging health issue linked to an increased rate of low birth weight infants. J Pediatr 2008; 153: 712-715.

24. Greco MF, Frieden IJ, Drolet BA, et al. Infantile hemangiomas in twins: A prospective cohort study. Pediatr Dermatol 2016; 33: 178-183. 